\title{
Synthesis and Crystal Structures of Two New Schiff Base Hydrazones Derived from Biphenyl-4-Carbohydrazide
}

\author{
Grzegorz Dutkiewicz $\cdot$ B. Narayana $\cdot$ \\ S. Samshuddin $\cdot$ H. S. Yathirajan $\cdot$ Maciej Kubicki
}

Received: 21 February 2011/Accepted: 29 April 2011/Published online: 10 May 2011

(C) The Author(s) 2011. This article is published with open access at Springerlink.com

\begin{abstract}
The crystal structures of two novel Schiff base hydrazones have been determined by means of the X-ray diffraction. These compounds: $N^{\prime}$-[(E)-(2,5-dimethoxyphenyl) methylidene]biphenyl-4-carbohydrazide, $\mathrm{C}_{22} \mathrm{H}_{20} \mathrm{~N}_{2} \mathrm{O}_{3}(\mathbf{1})$ and $\quad N^{\prime}$-[(E)-(4-fluorophenyl)methylidene $]$ biphenyl-4-carbohydrazide, $\mathrm{C}_{20} \mathrm{H}_{15} \mathrm{FN}_{2} \mathrm{O}$ (2), are the first structurally characterized biphenyl derivatives of phenylmethylidenecarbohydrazide. Both compounds crystallize in the monoclinic space groups, $\mathbf{1}$ in $\mathrm{P} 2_{1} / \mathrm{c}$ space group with $a=13.987(2) \AA, b=16.426(3) \AA, c=8.214(2) \AA, \beta=$ 98.12(2) ${ }^{\circ}$, and 2 in $\mathrm{C} 2 / \mathrm{c}$ with $a=37.163(5) \AA, b=$ $10.696(2) \AA, c=8.098(2) \AA, \beta=101.18(2)^{\circ}$. Both molecules have very similar bond lengths and angles pattern, even in the differently substituted phenyl ring. However, the conformations of the molecules differ significantly, the more crowded molecule $\mathbf{1}$ is much more folded than $\mathbf{2}$. The dihedral angle between the terminal ring planes is $56.17(6)^{\circ}$ in $\mathbf{1}$ while in $\mathbf{2}$ it is as small as $2.83(14)^{\circ}$. In both structures relatively short and linear $\mathrm{N}-\mathrm{H} \cdots \mathrm{O}$ hydrogen bonds (created by the best available hydrogen bond donor and acceptor) connect molecules into the chains along the unit cell parameter of ca. $8 \AA$ in length. The next stage of the crystal architecture determination, the secondary
\end{abstract}

G. Dutkiewicz · M. Kubicki $(\bowtie)$

Department of Chemistry, Adam Mickiewicz University, Grunwaldzka 6, 60-780 Poznan, Poland

e-mail: mkubicki@amu.edu.pl

B. Narayana $\cdot$ S. Samshuddin

Department of Studies in Chemistry, Mangalore University, Mangalagangotri 574 199, India

H. S. Yathirajan

Department of Studies in Chemistry, University of Mysore,

Manasagangotri, Mysore 570 006, India interactions, are however quite different: in $\mathbf{1}$ there are almost solely dispersion van der Waals interactions while in 2 some more specific $\mathrm{C}-\mathrm{H} \cdots \mathrm{F}$ and $\mathrm{C}-\mathrm{H} \cdots \pi$ interactions are also involved in the crystal packing.

Keywords Schiff bases · Hydrazones - Crystal structure · Weak interactions

\section{Introduction}

Schiff base hydrazones play an important role in inorganic chemistry, as they easily form stable complexes with most transition metal ions. The development of the field of bioinorganic chemistry has increased the interest in Schiff base complexes, since it has been recognized that many of these complexes may serve as models for biologically important species (e.g. [1, 2]). Coordination compounds derived from aroylhydrazones have been reported to act as enzyme inhibitors and are useful due to their pharmacological applications (e.g. [3-5]).

Hydrazones containing an azomethine $-\mathrm{NHN}=\mathrm{CH}-$ proton are synthesized by heating the appropriate substituted hydrazines/hydrazides with aldehydes and ketones in solvents like ethanol, methanol, tetrahydrofuran, butanol, glacial acetic acid, ethanol-glacial acetic acid. Another synthetic route for the synthesis of hydrazones is the coupling of aryldiazonium salts with active hydrogen compounds [6].

In course of our studies on the different medium and weak interactions that are responsible for the crystal packing we have synthesized and solved the crystal structures of two new Schiff bases, namely $N^{\prime}$-[(E)-(2,5-dimethoxyphenyl)methylidene]biphenyl-4-carbohydrazide, $\mathrm{C}_{22} \mathrm{H}_{20} \mathrm{~N}_{2} \mathrm{O}_{3}(\mathbf{1})$ and $N^{\prime}$ [(E)-(4-fluorophenyl)methylidene]biphenyl-4-carbohydrazide, 


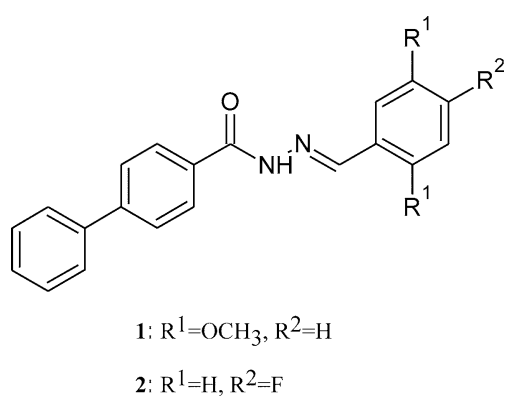

Scheme 1 Structures of Schiff base hydrazones

$\mathrm{C}_{20} \mathrm{H}_{15} \mathrm{FN}_{2} \mathrm{O}$ (2), cf. Scheme 1. Although there is a number of crystal structures of benzaldehyde-benzoylhydrazone derivatives (the Version 5.31 of the Cambridge Structural Database [7] updated November 2010 produces 257 hits containing this structural fragment) to the best of our knowledge the compounds described here are the first examples of biphenyl-containing derivatives.

Because the packing of the molecules in crystals results as the compromise between different factors including e.g. intermolecular interactions, studying of the packing regularities and differences in the crystals built of similar molecules might be useful in the area of supramolecular chemistry (e.g. [8, 9] and references therein). In both $\mathbf{1}$ and 2 one can find one good hydrogen bond donor $(\mathrm{NH})$ and one $\mathrm{C}=\mathrm{O}$ group that might act as hydrogen bond acceptor. Therefore it could be anticipated that the main packing motif is a chain of hydrogen bond molecules, probably related by a screw axis or a glide plane. However the packing of the chains has to be determined by other interactions and requirements, which in this case would be among such factors as close packing, van der Waals interactions, weak hydrogen bonds $(\mathrm{C}-\mathrm{H} \cdots \mathrm{O}, \mathrm{F}, \mathrm{N}$ or $\pi$ ), $\pi-\pi$ stacking etc. Studies on such closely related but different systems might be useful in gaining the better understanding of the factors that influence the crystal packing.

\section{Experimental}

Synthesis

Synthesis of $N^{\prime}-[(E)$-(2,5-dimethoxyphenyl)

methylidene]biphenyl-4-carbohydrazide (1)

Biphenyl-4-carbohydrazide $(0.01 \mathrm{~mol}, 2.12 \mathrm{~g})$ and 2,5 dimethoxy benzaldehyde $(1.66 \mathrm{~g}, 0.01 \mathrm{~mol})$ were dissolved in ethanol $(30 \mathrm{~mL})$ and added two drops of Conc. $\mathrm{HCl}$. Refluxed the mixture for about $3 \mathrm{~h}$. On cooling, the solid separated was filtered, washed with water and dried. Good quality crystals were grown from DMF solution by slow evaporation (m.p.: 495 K). Composition: Found (Calculated): C: 38.39 (38.47); H: 3.17 (3.23); N: $22.35 \%$ (22.43\%).

Synthesis of $N^{\prime}-[(E)$-(4-fluorophenyl)methylidene] biphenyl-4-carbohydrazide (2)

Biphenyl-4-carbohydrazide ( $0.01 \mathrm{~mol}, 2.12 \mathrm{~g}$ ) and 4-fluoro benzaldehyde $(1.24 \mathrm{~g}, 0.01 \mathrm{~mol})$ were dissolved in ethanol $(30 \mathrm{~mL})$ and added two drops of Conc. HCl. Refluxed the mixture for about $3 \mathrm{~h}$. On cooling, the solid separated was filtered, washed with water and dried. Good quality crystals were grown from DMF solution by slow evaporation (m.p.: 519 K). Composition: Found (Calculated): C: 75.39(75.46); H: 4.68 (4.75); N: 8.74\% (8.80\%).

\section{X-ray Structure Determination}

Diffraction data were collected at room temperature by the $\omega$-scan technique, on an Oxford Diffraction SuperNova four-circle diffractometer equipped with Atlas CCDdetector [10] using mirror-monochromatized $\mathrm{CuK}_{\alpha}$ radiation from high-flux micro-focus source $(\lambda=1.54178 \AA$ ). The data were corrected for Lorentz-polarization as well as for absorption effects [10]. Accurate unit-cell parameters were determined by a least-squares fit of 5001 (1), and 7561 (2) reflections of highest intensity, chosen from the whole experiment. The structures were solved with SIR92 [11] and refined with the full-matrix least-squares procedure on $F^{2}$ by SHELXL97 [12]. Scattering factors incorporated in SHELXL97 were used. The function $\Sigma w\left(\left|F_{\mathrm{o}}\right|^{2}-\left|F_{\mathrm{c}}\right|^{2}\right)^{2}$ was minimized, with $w^{-1}=\left[\sigma^{2}\left(F_{\mathrm{o}}\right)^{2}+(A P)^{2}+B P\right]$, where $P=\left[\operatorname{Max}\left(F_{\mathrm{o}}^{2}, 0\right)+2 F_{\mathrm{c}}^{2} / 3\right]$. The final values of $A$ and $B$ are listed in Table 1 together with relevant crystal data and refinement details. All non-hydrogen atoms were refined anisotropically. The hydrogen atoms from the methyl groups in 1 were placed geometrically, in idealized positions $(\mathrm{C}-\mathrm{H}$ distances of $0.96 \AA$ ), and refined as rigid groups with their $U_{\text {iso }}$ 's as 1.5 times $U_{\text {eq }}$ of the appropriate carrier atom. All other hydrogen atoms were found in the difference Fourier maps and isotropically refined.

Crystallographic data (excluding structure factors) for the structural analysis has been deposited with the Cambridge Crystallographic Data Centre, Nos. CCDC-813832 (1), and CCDC-813833 (2). Copies of this information may be obtained free of charge from: The Director, CCDC, 12 Union Road, Cambridge, CB2 1EZ, UK. Fax: +44(1223)336-033, e-mail:deposit@ccdc.cam.ac.uk, or www: www.ccdc.cam.ac.uk. 
Table 1 Crystal data, data collection and structure refinement

\begin{tabular}{|c|c|c|}
\hline Compound & 1 & 2 \\
\hline Formula & $\mathrm{C}_{22} \mathrm{H}_{20} \mathrm{~N}_{2} \mathrm{O}_{3}$ & $\mathrm{C}_{20} \mathrm{H}_{15} \mathrm{FN}_{2} \mathrm{O}$ \\
\hline Formula weight & 360.40 & 318.34 \\
\hline Crystal system & Monoclinic & Monoclinic \\
\hline Space group & $\mathrm{P} 2{ }_{1} / \mathrm{c}$ & $\mathrm{C} 2 / \mathrm{c}$ \\
\hline$T(\mathrm{~K})$ & $295(2)$ & $295(2)$ \\
\hline$a(\AA)$ & $13.987(2)$ & $37.163(5)$ \\
\hline$b(\AA)$ & $16.426(3)$ & $10.696(2)$ \\
\hline$c(\AA)$ & $8.214(2)$ & $8.098(2)$ \\
\hline$\beta\left(^{\circ}\right)$ & $98.12(2)$ & $101.18(2)$ \\
\hline$V\left(\AA^{3}\right)$ & $1868.3(6)$ & $3157.8(11)$ \\
\hline$Z$ & 4 & 8 \\
\hline$D_{x}\left(\mathrm{~g} \mathrm{~cm}^{-3}\right)$ & 1.28 & 1.34 \\
\hline$F(000)$ & 760 & 1328 \\
\hline$\mu\left(\mathrm{mm}^{-1}\right)$ & 0.70 & 0.75 \\
\hline Crystal size (mm) & $0.3 \times 0.1 \times 0.1$ & $0.3 \times 0.2 \times 0.15$ \\
\hline$\Theta$ range $\left(^{\circ}\right)$ & 3.19-75.09 & $4.31-75.06$ \\
\hline \multirow[t]{3}{*}{ hkl range } & $-17 \leq \mathrm{h} \leq 10$ & $-46 \leq \mathrm{h} \leq 41$ \\
\hline & $-20 \leq \mathrm{k} \leq 18$ & $-13 \leq \mathrm{k} \leq 8$ \\
\hline & $-10 \leq 1 \leq 9$ & $-10 \leq 1 \leq 9$ \\
\hline \multicolumn{3}{|l|}{ Reflections } \\
\hline Collected & 7161 & 8344 \\
\hline Unique $\left(R_{\text {int }}\right)$ & $3690(0.013)$ & $3156(0.025)$ \\
\hline With $I>2 \sigma(I)$ & 3239 & 2974 \\
\hline Number of parameters & 302 & 278 \\
\hline \multicolumn{3}{|l|}{ Weighting scheme } \\
\hline$A$ & 0.0638 & 0.0499 \\
\hline$B$ & 0.1742 & 3.4051 \\
\hline$R(F)[I>2 \sigma(I)]$ & 0.040 & 0.060 \\
\hline$w R\left(F^{2}\right)[I>2 \sigma(I)]$ & 0.110 & 0.141 \\
\hline$R(F)$ [all data] & 0.044 & 0.061 \\
\hline$w R\left(F^{2}\right)$ [all data] & 0.113 & 0.142 \\
\hline Goodness of fit & 1.056 & 1.071 \\
\hline $\operatorname{Max} / \min \Delta \rho\left(\mathrm{e} \AA^{-3}\right)$ & $0.14 /-0.17$ & $0.20 /-0.21$ \\
\hline
\end{tabular}

\section{Results}

Figures 1 and 2 show the perspective views of the molecules 1 and 2, respectively. Table 2 compares the relevant geometric parameters of both molecules. The bond lengths and angles in both compounds are very similar; a majority of them differ by less than $3 \sigma$, and even the results of the normal probability plot test $[13,14]$ confirm that the differences between the molecules are mainly of statistic nature.

The correlation coefficient $R^{2}$ between the set of experimental differences between the geometrical parameters and the theoretical values for pure statistical distribution is 0.967 for the bond lengths (excluding C14-C141 and C14-F14 bonds) and 0.984-for angles. Of course the

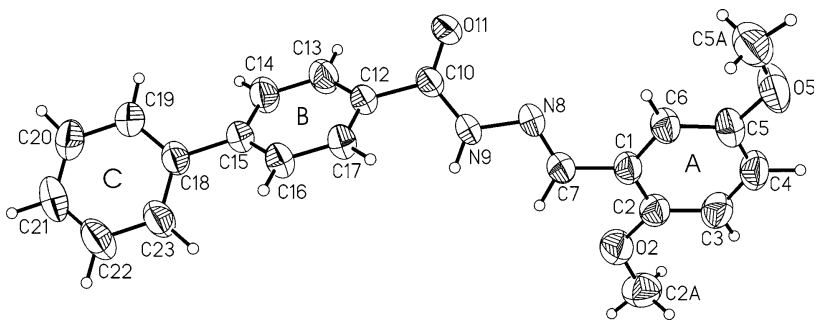

Fig. 1 Anisotropic ellipsoid representation of the compound 1 together with atom labeling scheme [11]. The ellipsoids are drawn at $50 \%$ probability level, hydrogen atoms are shown as spheres of arbitrary radii

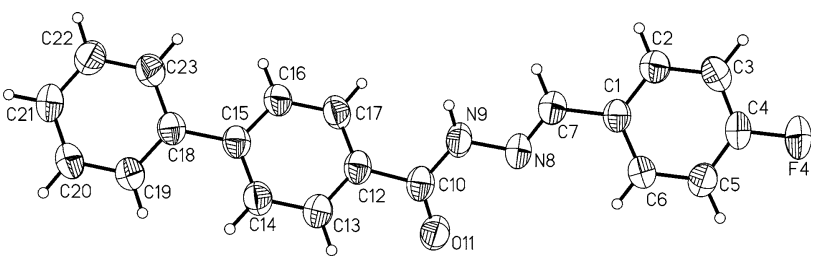

Fig. 2 Anisotropic ellipsoid representation of the compound 2 together with atom labeling scheme [11]. The ellipsoids are drawn at $50 \%$ probability level, hydrogen atoms are shown as spheres of arbitrary radii

Table 2 Selected geometrical parameters $\left(\AA 0^{\circ}\right)$ with su's in parentheses

\begin{tabular}{lrr}
\hline & 1 & \multicolumn{1}{c}{} \\
\hline C1-C7 & $1.491(4)$ & $1.483(5)$ \\
C7-N8 & $1.218(3)$ & $1.210(4)$ \\
N8-N9 & $1.478(4)$ & $1.484(5)$ \\
N9-C10 & $1.326(4)$ & $1.328(4)$ \\
C10-O11 & $1.452(4)$ & $1.449(4)$ \\
C15-C18 & & \\
C1-C2-C3 & $119.3(3)$ & $117.7(3)$ \\
C2-C3-C4 & $120.8(3)$ & $122.0(3)$ \\
C3-C4-C5 & $129.2(3)$ & $128.3(3)$ \\
C4-C5-C6 & $120.4(3)$ & $121.0(3)$ \\
C5-C6-C1 & $118.5(4)$ \\
C6-C1-C2 & $121.5(3)$ & $122.8(4)$ \\
C1-C7-N8 & $118.3(3)$ & $118.1(4)$ \\
C7-N8-N9 & $120.1(3)$ & $121.6(4)$ \\
C2-C1-C7-N8 & $122.4(3)$ & $168.09(19)$ \\
C1-C7-N8-N9 & $-158.07(12)$ & $177.06(17)$ \\
C7-N8-N9-C10 & $-176.66(11)$ & $-176.37(18)$ \\
N8-N9-C10-C12 & $-155.61(12)$ & $176.33(16)$ \\
N9-C10-C12-C13 & $-178.09(10)$ & $-147.98(19)$ \\
C14-C15-C18-C19 & $-138.94(13)$ & $-23.3(3)$ \\
B/C & $-34.02(21)$ & $23.14(10)$ \\
A/C & $33.48(5)$ & $56.17(6)$ \\
\hline
\end{tabular}


different substituents in ring A cause the differences in the intraannular bond angles patterns-as observed for instance by Domenicano and Murray-Rust [15, 16]-but it seems that in this case, due to the various positions of these substituents, the differences mainly cancel out.

The overall conformations of $\mathbf{1}$ and $\mathbf{2}$ differ, and it can be related to the presence or absence of the substituent in the ortho position of the ring A, even though it seems that

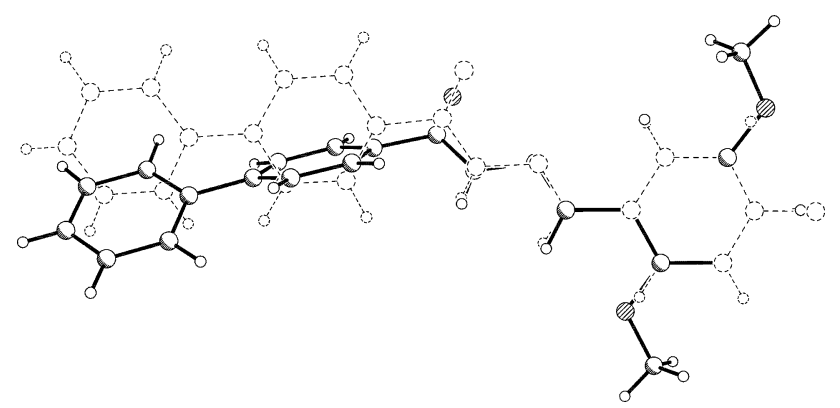

Fig. 3 The comparison of the molecules of $\mathbf{1}$ (dashed) and $\mathbf{2}$ (solid); the rings A were fitted onto one another [11] there is enough space for methoxy group to accommodate and the CSD data do not show the clear conformational preferences. The overall shape of these molecules can be described by the dihedral angles between three planar fragments (cf. Fig. 1 for the nomenclature; Table 2 for appropriate values). In $\mathbf{1}$ the central $\mathrm{C}=\mathrm{N}-\mathrm{N}-\mathrm{C}=\mathrm{O}$ chain is relatively far from the planarity, the atoms $\mathrm{N} 8, \mathrm{~N} 9, \mathrm{C} 10$, $\mathrm{O} 11$ and $\mathrm{C} 12$ are coplanar within $0.018 \AA$ while N7 deviates from that mean plane by as much as $0.488(2) \AA$. This mean plane makes the dihedral angle of $50.68(6)^{\circ}$ with the plane of ring $\mathrm{A}$ and $39.92(5)^{\circ}$ with that of ring $\mathrm{B}$. In 2 the whole $\mathrm{C}=\mathrm{N}-\mathrm{N}-\mathrm{C}=\mathrm{O}$ chain is planar within $0.019(1) \AA$, and it makes similar to previously given dihedral angle with $\mathrm{B}, 33.32(15)^{\circ}$, while the twist with respect to the ring $\mathrm{A}$ is significantly smaller, $12.89(15)^{\circ}$. The biphenyl fragments in both molecules are twisted but also in this case the twist angle is greater in $\mathbf{1}$, the dihedral angle between mean planes of phenyl rings is $33.48(5)^{\circ}$ in 1 and $23.14(10)^{\circ}$ in 2 . The terminal rings $\mathrm{A}$ and $\mathrm{C}$ are significantly twisted in $\mathbf{1}\left(56.17(6)^{\circ}\right)$ while they are almost coplanar in $2\left(2.83(14)^{\circ}\right)$. The comparison of both
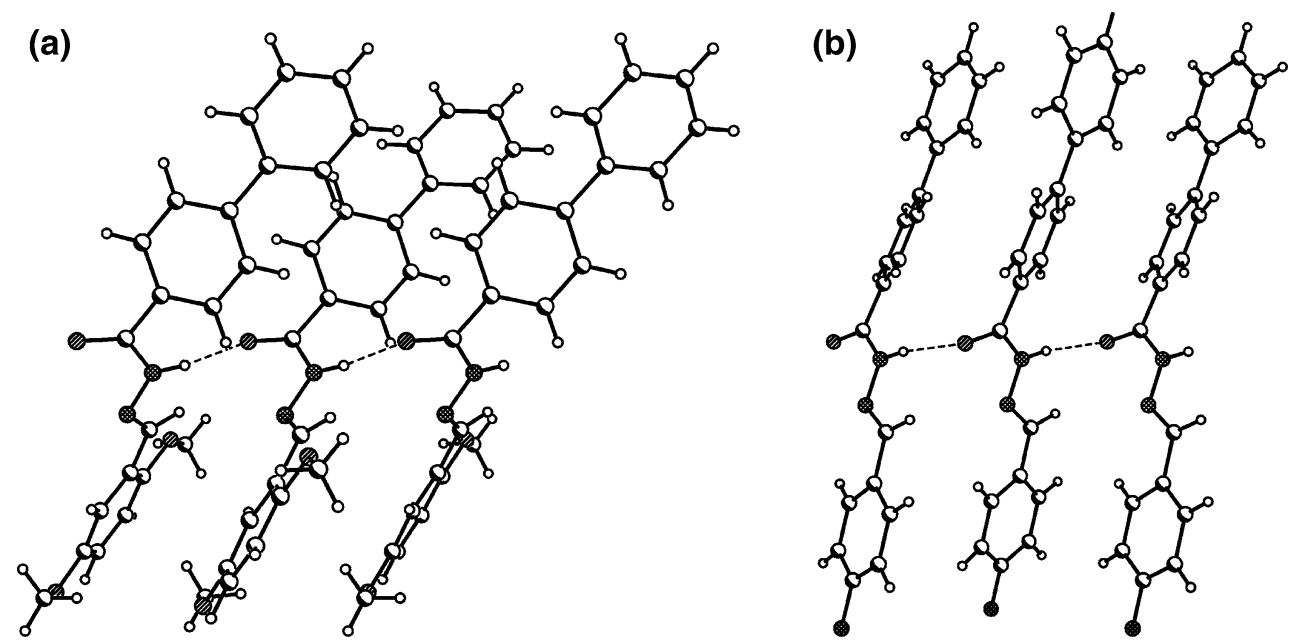

Fig. 4 The hydrogen bonded chains of molecules 1 (a) and $\mathbf{2}$ (b) as seen approximately along $y$ direction. Hydrogen bonds are shown as dashed lines [11]

Table 3 Hydrogen bond data

\begin{tabular}{|c|c|c|c|c|c|c|}
\hline D & $\mathrm{H}$ & A & D-H $(\AA)$ & $\mathrm{H} \cdots \mathrm{A}(\AA)$ & $\mathrm{D} \cdots \mathrm{A}(\AA)$ & $\mathrm{D}-\mathrm{H} \cdots \mathrm{A}\left({ }^{\circ}\right)$ \\
\hline \multicolumn{7}{|l|}{1} \\
\hline N9 & H9 & $\mathrm{O} 11^{\mathrm{i}}$ & $0.883(17)$ & $1.999(18)$ & $2.8729(15)$ & $169.9(15)$ \\
\hline \multicolumn{7}{|l|}{2} \\
\hline N9 & H9 & $\mathrm{O} 11^{\mathrm{ii}}$ & $0.86(2)$ & $2.05(2)$ & $2.906(2)$ & $170(2)$ \\
\hline C5 & H5 & $\mathrm{F} 4^{\mathrm{iii}}$ & $0.94(2)$ & $2.67(2)$ & $3.458(3)$ & $142.4(19)$ \\
\hline C19 & H19 & $\mathrm{CgA}^{\mathrm{iv}}$ & $0.93(2)$ & $2.85(2)$ & $3.609(3)$ & $140.2(17)$ \\
\hline $\mathrm{C} 22$ & $\mathrm{H} 22$ & $\mathrm{CgC}^{\mathrm{v}}$ & $0.93(2)$ & $2.91(2)$ & $3.656(3)$ & $137.2(18)$ \\
\hline
\end{tabular}

Symmetry codes: ${ }^{\mathrm{i}} x,-y+1 / 2, z+1 / 2 ;{ }^{\mathrm{ii}} x, 2-y, z+1 / 2 ;{ }^{\mathrm{iii}} 1-x, 2-y,-z ;{ }^{\mathrm{iv}} 3 / 2-x, 1 / 2+y, 1 / 2-z ;{ }^{\mathrm{v}} x, 2-y, 1 / 2+z$ 

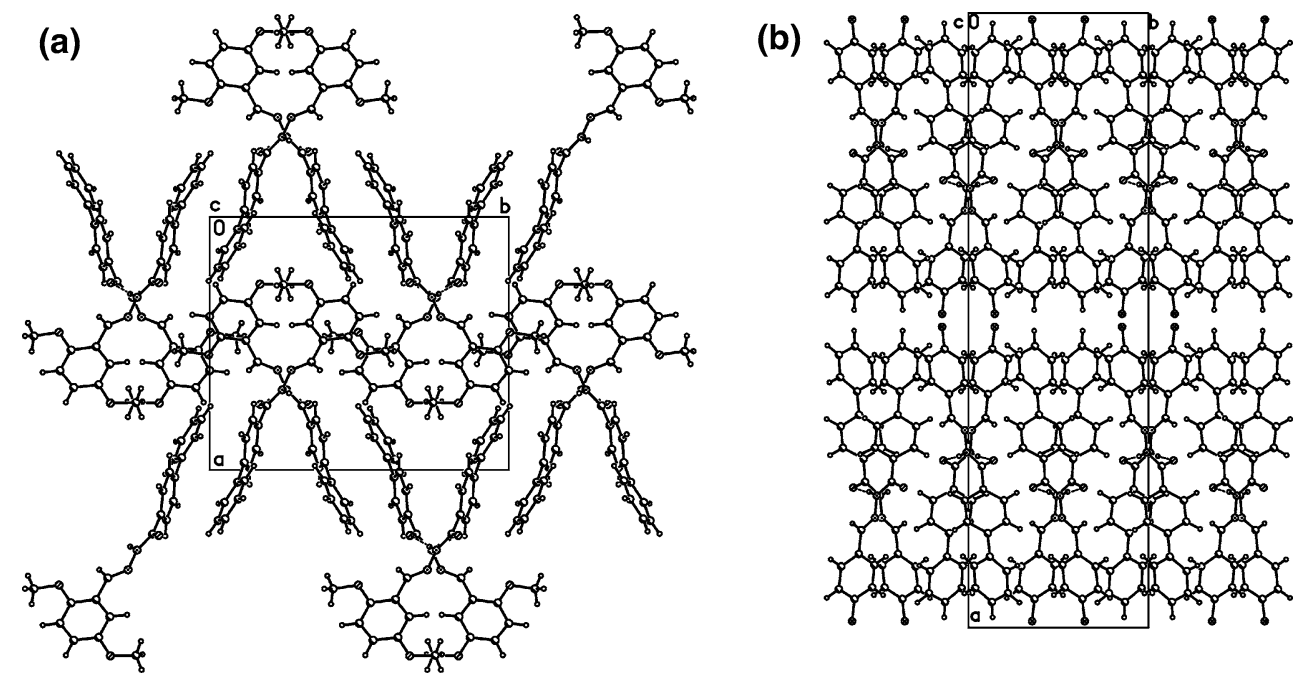

Fig. 5 The crystal packing as seen along the direction of hydrogen bonded chains in $\mathbf{1}$ (a) and $\mathbf{2}$ (b) [11]

molecules, fitted onto their rings A, is shown in Fig. 3. The geometries of both $\mathbf{1}$ and $\mathbf{2}$ are well within the typical ranges.

These quite closely related molecules turned out to show to some extent different organisation in the crystal structure. As expected, in both cases the $\mathrm{N}-\mathrm{H} \cdots \mathrm{O}$ hydrogen bonds, relatively linear, connect molecules into the infinite chains of molecules connected by the $c$-glide plane. In both cases therefore the chains extend along [001] direction (cf. Fig. 4a, b; Table 3), and in both structures-despite different space groups - the unit cell parameters c have similar values (8.214 $\AA$ in $\mathbf{1}, 8.098 \AA$ in $\mathbf{2})$.

The next levels of the structure organizations are however different, which can be caused by the differences in the molecular conformations. In $\mathbf{1}$ there are virtually no specific interactions which might play a role in the designing of the crystal structure. Therefore only close packing requirements and van der Waals forces are involved in the crystal structure. Contrary, in $\mathbf{2}$ there is some weak but definitely directional $\mathrm{C}-\mathrm{H} \cdots \mathrm{F}$ interactions, and two-probably also of some importance- $\mathrm{C}-\mathrm{H} \cdots \pi$ contacts with aromatic rings playing role of very weak acceptor of a hydrogen-bond-like interaction (cf. Table 3). These subtle differences lead to quite dissimilar mode of packing of the hydrogen-bonded chains (Fig. 5).

Acknowledgment BN thanks UGC, New Delhi, Government of India for the purchase of chemicals through SAP-DRS-Phase 1 programme.

Open Access This article is distributed under the terms of the Creative Commons Attribution Noncommercial License which permits any noncommercial use, distribution, and reproduction in any medium, provided the original author(s) and source are credited.

\section{References}

1. Jeeworth T, Wah HLK, Bhowon MG, Ghoorhoo D, Babooram K (2000) Synth React Inorg Met-Org Chem 30:1023

2. Dharmaraj N, Viswanalhamurthi P, Natarajan K (2001) Transit Met Chem 26:105

3. Savanini L, Chiasserini L, Gaeta A, Pellerano C (2002) Biorg Med Chem 10:2193

4. Ferrari MB, Capacchi S, Pelosi G, Reffo G, Tarasconi P, Alberlini R, Pinelli S, Lunghi P (1999) Inorg Chim Acta 286:134

5. Dharmaraj N, Viswanalhamurthi P, Natarajan K (2001) Transit Met Chem 26:105

6. Rollas S, Kucukguzel SG (2007) Molecules 12:1910

7. Allen FH (2002) Acta Crystallogr B58:380

8. Brock CP, Dunitz JD (1994) Chem Mater 6:1118

9. Kubicki M (2005) J Mol Struct 743:209

10. Agilent Technologies (2010) CrysAlis PRO (version 1.171.35.4). Agilent Technologies Ltd, Yarnton

11. Altomare A, Cascarano G, Giacovazzo C, Gualardi A (1993) J Appl Crystallogr 26:343

12. Sheldrick GM (2008) Acta Crystallogr A64:112

13. Abrahams SC, Keve ET (1971) Acta Crystallogr A27:157

14. (1974) International tables for X-ray crystallography, vol IV. Kluwer, Dordrecht, p 293

15. Domenicano A, Murray-Rust P (1979) Tetrahedron Lett 24:2283

16. Domenicano A (1988) In: Hargittai I, Hargittai M (eds) Stereochemical applications of gas-phase electron diffraction. Part B: Structural information for selected classes of compounds. VCH, Weinheim, p 281 